\title{
Growth Mechanisms and Structural Properties of Lead Chalcogenide Films Grown by Pulsed Laser Deposition
}

\author{
I.S. VIRT, ${ }^{1,2}$ I.O. RUDYI ${ }^{3}$ I. YE. LOPATYNSKYI ${ }^{3}$ YU. DUBOV,${ }^{4}$ Y. TUR, ${ }^{1}$ \\ E. LUSAKOWSKA, ${ }^{5}$ and G. LUKA ${ }^{5,6}$ \\ 1.-Drogobych State Pedagogical University, Drogobych, Ukraine. 2.-University of Rzeszow, \\ Rzeszow, Poland. 3.-Lviv Polytechnic, National University, Lviv, Ukraine. 4.-Ivan Franko Lviv \\ National University, Lviv, Ukraine. 5.-Institute of Physics PAS, Warsaw, Poland. 6.-e-mail: \\ gluka@ifpan.edu.pl
}

\begin{abstract}
Three lead chalcogenide films, $\mathrm{PbTe}, \mathrm{PbSe}$, and $\mathrm{PbS}$, with a high structural quality were grown by pulsed lased deposition (PLD). The films were grown on single crystal substrates $\left(\mathrm{Si}, \mathrm{KCl}, \mathrm{Al}_{2} \mathrm{O}_{3}\right)$ and on $\mathrm{Si}$ covered with a $\mathrm{Si}_{3} \mathrm{~N}_{4}$ buffer layer. The $\mathrm{Si}_{3} \mathrm{~N}_{4}$ layer latter facilitated the lead chalcogenide layer nucleation during the first growth stages and resulted in a more homogeneous surface morphology and a lower surface roughness. The surface geometry (roughness) of the films grown on $\mathrm{Si}_{3} \mathrm{~N}_{4}$ was studied by means of the power spectral density analysis. Different growth modes, ranging from plasma plume condensation to bulk diffusion, resulting in observed film morphologies were identified. The investigations were complemented by electrical characterization of the chalcogenide films.
\end{abstract}

Key words: Lead chalcogenides, film structure, pulsed laser deposition

\section{INTRODUCTION}

An increased interest in $\mathrm{A}^{\mathrm{IV}} \mathrm{B}^{\mathrm{VI}}$ compounds stems from their excellent ability to detect infrared (IR) radiation in a wide wavelength range. This explains practical applications of these compounds in various optoelectronic devices. ${ }^{1-6}$ Lead chalcogenides $(\mathrm{PbS}$, $\mathrm{PbSe}$ and $\mathrm{PbTe}$ ) are especially good materials for mid-wave IR (wavelength of $2.5 \mu \mathrm{m}$ ) detection. They also have good chemical and mechanical stability. Especially promising for IR optoelectronics are $\mathrm{A}^{\mathrm{IV}} \mathrm{B}^{\mathrm{VI}}$ doped semiconductors and their solid solutions. The range of detection wavelengths can be extended, i.e. from mid-wave IR to far-IR region, by tin alloying. In addition, other systems such as $\mathrm{HgCdTe}$ are quite sensitive to crystal defects and, therefore, only $\mathrm{HgCdTe}$ single crystals are useful for efficient IR detection. In contrast to this, polycrystalline lead chalcogenides may exhibit higher sensitivity compared to their single crystalline counterparts. ${ }^{7}$ This unique feature enables preparation of chalcogenide detector systems integrated

(Received May 20, 2016; accepted August 20, 2016;

published online September 8, 2016) with silicon technology. This integration illustrates a competitive advantage of lead chalcogenides over HgCdTe systems. ${ }^{7,8}$

Polycrystalline chalcogenide films grown by physical vapor deposition methods usually have $n$-type conductivity due to deviation from stoichiometry, i.e. due to excess lead or chalcogen deficiency. ${ }^{9}$ The latter case can be an effect of lower adhesion of chalcogen atoms to the surface of the growing layer. $\mathrm{PbSe}$ films deposited from solution and used in commercial IR detectors often exhibit high stability, but there is a lack of information about the certain electrical parameters like free carrier concentrations in these films. Polycrystalline lead chalcogenide films like $\mathrm{PbSe}$ or $\mathrm{PbS}$, exhibiting high $\mathrm{IR}$ sensitivity, usually have a microstructure composed of large size grains, from $0.4 \mu \mathrm{m}$ to $0.9 \mu \mathrm{m}$. For comparison, nanocrystalline $\mathrm{PbTe}$ films with a grain size of $50-75 \mathrm{~nm}$ are more easily saturated with oxygen (by diffusion) and show good photosensitivity. In $\mathrm{PbTe}$ polycrystalline films, free carrier concentrations of $10^{18} \mathrm{~cm}^{-3}$ are usually reported. ${ }^{9}$

In this work, we obtained and studied lead chalcogenide films, $\mathrm{PbTe}, \mathrm{PbSe}$, and $\mathrm{PbS}$, that were grown by pulsed laser deposition (PLD) and have 
high structural quality. We analyzed the film structure, mechanical and electrical properties, as well as surface morphology of the deposited layers. Our aim was to acquire information about growth mechanisms and crystal structure formation of lead chalcogenides grown by PLD, which is one of the most prospective methods for lead chalcogenide film epitaxy.

\section{EXPERIMENTAL}

$\mathrm{PbTe}, \mathrm{PbSe}$, and PbS films were obtained by PLD using stoichiometric targets. The targets were prepared from $\mathrm{Pb}, \mathrm{S}$, Se, and Te elements having $5 \mathrm{~N}$ purity, and placed in quartz ampoules under vacuum to carry out the synthesis reaction. We used a YAG: $\mathrm{Nd}^{3+}$ laser with the following parameters: the laser wavelength was $1064 \mathrm{~nm}$, the energy maximum in a pulse was $0.4 \mathrm{~J}$, the power density was $4 \times 10^{8} \mathrm{~W} / \mathrm{cm}^{2}$, the pulse duration was $10 \mathrm{~ns}$, and the pulse frequency was $0.5 \mathrm{~Hz}$. The pressure inside the PLD chamber was $1 \times 10^{-5} \mathrm{~mm} \mathrm{Hg}$, and the substrate temperature was $200^{\circ} \mathrm{C}$. We used $\mathrm{KCl}(001)$, $\mathrm{Si}(111)$, and $\mathrm{Si}_{3} \mathrm{~N}_{4} / \mathrm{Si}$ substrates. The latter substrates were prepared by depositing an $\mathrm{Si}_{3} \mathrm{~N}_{4}$ buffer layer on $\mathrm{Si}(111)$ by PLD. ${ }^{10-12}$ The $\mathrm{Si}_{3} \mathrm{~N}_{4}$ layer thickness was $110 \mathrm{~nm}$. The thickness of each lead chalcogenide film was $2 \mu \mathrm{m}$.

The structure and homogeneity of the synthesized PLD target materials were studied by x-ray diffraction (XRD) using a DRON-3.0 diffractometer with $\mathrm{CuK} \alpha$ radiation and $\theta-\theta$ scanning. The structural quality of the respective films was investigated by transmission high-energy electron diffraction (THEED) for the samples grown on $\mathrm{KCl}(001)$ substrates. We used an EMR-100 electron diffractometer with the acceleration voltages of $60-80 \mathrm{kV}$.

Surface morphology of the deposited films was investigated by atomic force microscopy (AFM; Nanoscope II, Veeco) in the tapping mode. AFM surface geometry (roughness) was studied by means of the power spectral density (PSD) analysis. ${ }^{13,14}$ The PSD function, $F_{\mathrm{PSD}}$, is the Fourier transform of the power function $P=h^{2}\left(\mathrm{~nm}^{2}\right)$, where $h$ is the profile height at a given point. The investigated film lengths were $L=2 \mu \mathrm{m}$ and the number of data points were $m=512$. This gave the sampling distance $\Delta L=L / m \approx 3.9 \mathrm{~nm}$. Therefore, the lower and upper bandwidth of the $F_{\mathrm{PSD}}$ was $5 \times 10^{-4} \mathrm{~nm}^{-1}$ and $\approx 0.26 \mathrm{~nm}^{-1}$, respectively. The $F_{\mathrm{PSD}}$ data were fitted using the k-correlation model ${ }^{14}$

$$
F_{\mathrm{PSD}}=\frac{A}{\left(1+B^{2}\left(L^{-1}\right)^{2}\right)^{\frac{C+1}{2}}}
$$

where $A, B$, and $C$ are the fit parameters.

Temperature-dependent electrical conductivities of the films grown on $\mathrm{Al}_{2} \mathrm{O}_{3}(0001)$ substrates were measured in the $300-400 \mathrm{~K}$ range. We chose $\mathrm{Al}_{2} \mathrm{O}_{3}$ because of its good dielectric properties, good thermal conductivity and mechanical stability at a very

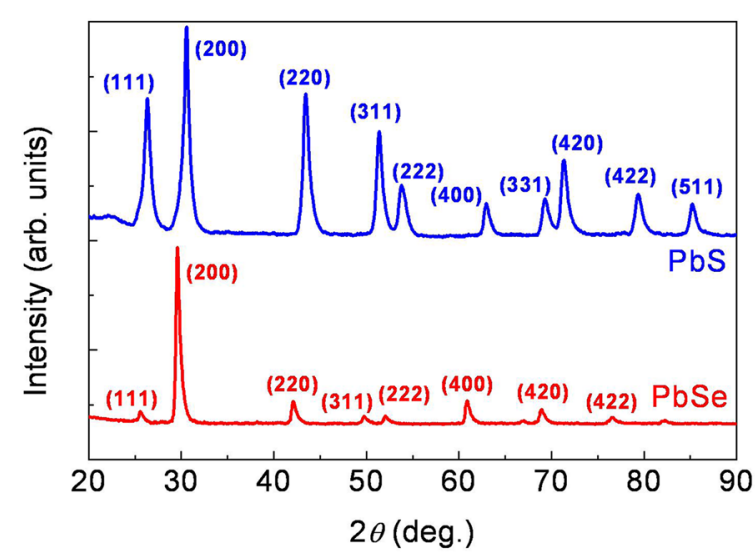

Fig. 1. XRD patterns of PbSe and PbS targets.

wide range of temperatures. For the measurements, silver metal contacts were thermally evaporated on the samples in vacuum through shadow masks. The activation energies $E_{\text {a }}$ were calculated using the formula

$$
\sigma(T)=\sigma_{0} \exp \left(-\frac{E_{\mathrm{a}}}{k T}\right)
$$

where $\sigma_{0}$ is a constant, $k$ is the Boltzmann constant and $T$ is absolute temperature.

\section{RESULTS AND DISCUSSION}

The XRD patterns of PbSe and PbS target powders are shown in Fig. 1. The XRD pattern of PbTe target was already analyzed elsewhere. ${ }^{15}$ All the patterns (including that of $\mathrm{PbTe}$ ) indicate the presence of only one face-centered cubic phase of $\mathrm{NaCl}$ for all the materials. Additionally, there are no peaks corresponding to the precipitation of any compounds or binary alloys. ${ }^{16-18}$ The calculated experimental interplanar distances $d_{\mathrm{khl}}$ are shown in Table I. They are very close to the standard data for bulk crystals. ${ }^{19}$

The THEED patterns of $\mathrm{PbTe}, \mathrm{PbSe}$, and $\mathrm{PbS}$ films deposited on $\mathrm{KCl}(001)$ substrates are shown and compared in Fig. 2. All the patterns consist of arced reflections corresponding to the Debye-Scherrer rings, according to the spread of grain orientations around the incident beam. From the patterns, we deduce that all the films contain one fcc phase of $\mathrm{NaCl}$. However, a degree of texture differs among the respective films. In case of the PbSe films, we observe long arced reflections indicating a larger crystallite disorientation, compared to $\mathrm{PbS}$ and PbTe films. The diffraction pattern of the PbTe film is composed of short and blurry reflections placed on the Debye-Scherrer rings. The PbS layer shows the highest degree of texture. Here, short arced reflections with high intensity placed on the DebyeScherrer rings are observed. The calculated lattice parameters are $6.462 \AA, 6.117 \AA$, and $5.922 \AA$ for $\mathrm{PbTe}, \mathrm{PbSe}$, and $\mathrm{PbS}$ films, respectively. They are 
Table I. Interplanar distances $d_{\mathrm{hkl}}$ for the given $(\mathrm{hkl})$ intensities of PbSe and PbS targets and films

\begin{tabular}{|c|c|c|c|c|c|}
\hline \multicolumn{3}{|c|}{ PbSe } & \multicolumn{3}{|c|}{$\mathbf{P b S}$} \\
\hline$h \boldsymbol{k l}$ & $\begin{array}{c}\boldsymbol{d}_{\mathbf{h k l}},(\stackrel{(\AA)}{\mathbf{A})} \\
\text { XRD target }\end{array}$ & $\begin{array}{c}\boldsymbol{d}_{\text {hkl }}(\AA) \\
\text { THEED } \\
\text { film }\end{array}$ & $h \boldsymbol{k l}$ & $\begin{array}{c}\boldsymbol{d}_{\mathbf{h k l}}(\stackrel{\AA}{\mathbf{A})} \\
\text { XRD target }\end{array}$ & 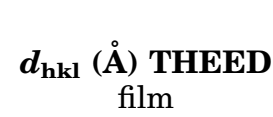 \\
\hline 111 & 3.4769 & 3.534 & 111 & 3.3830 & 3.422 \\
\hline 200 & 3.0184 & 3.062 & 200 & 2.9228 & 2.971 \\
\hline 220 & 2.1464 & 2.165 & 220 & 2.0833 & 2.094 \\
\hline 311 & 1.8331 & 1.844 & 311 & 1.7782 & 1.782 \\
\hline 222 & 1.7563 & 1.761 & 222 & 1.7050 & 1.706 \\
\hline 400 & 1.5217 & 1.529 & 400 & 1.4772 & 1.479 \\
\hline 331 & 1.3976 & 1.405 & 331 & 1.3620 & 1.378 \\
\hline 420 & 1.3629 & 1.364 & 420 & 1.3270 & 1.366 \\
\hline$a_{(200)}$ & 6.114 & 6.117 & & 5.927 & 5.922 \\
\hline$a_{\mathrm{st}}$ & & & & & \\
\hline$\Delta a / a_{\text {st }}$ & $-0.16 \%$ & $-0.11 \%$ & & $-0.15 \%$ & $-0.24 \%$ \\
\hline
\end{tabular}

The values were derived from XRD (Fig. 1) and THEED (Fig. 2) data, respectively. The lattice constants, indicated as $a_{(200)}$, were calculated using $d_{200}$ values. $a_{\text {st }}$ are the standard values taken from Ref. $19 . \Delta a / a_{\text {st }}=\left\{\left[a_{(200)}-a_{\text {st }}\right] / a_{\text {st }}\right\} \times 100 \%$.
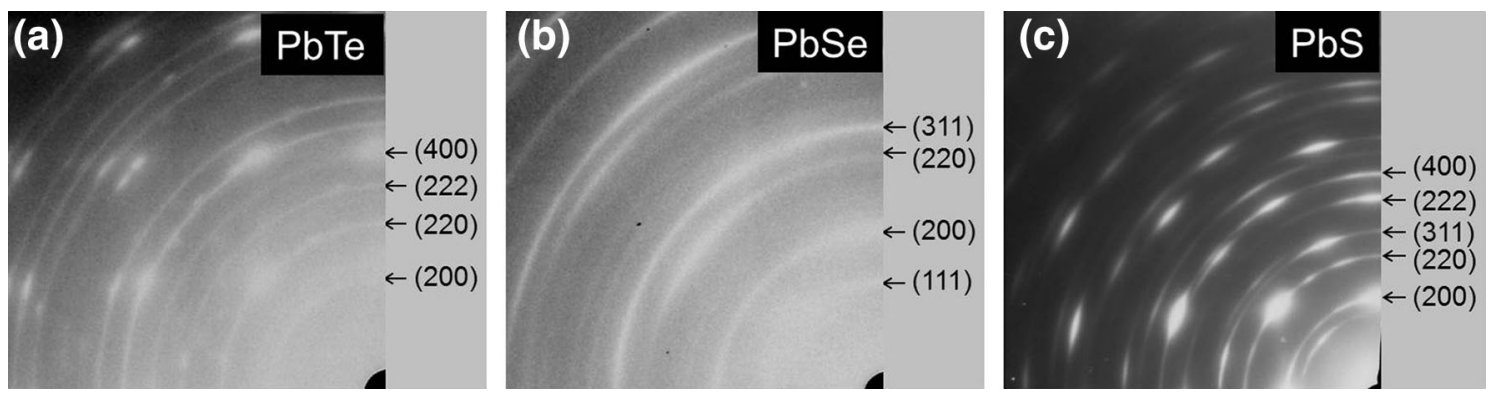

Fig. 2. THEED patterns of (a) PbTe, (b) PbSe, and (c) PbS films grown on $\mathrm{KCl}$ substrates. The most pronounced Miller indices (hkl) are indicated.

very close to the respective standard values $a_{\text {st }}$ for powder diffraction of these materials. ${ }^{19}$ The $\Delta a / a_{\text {st }}$ differences are $-0.13 \%,-0.11 \%$, and $-0.24 \%$ for $\mathrm{PbTe}, \mathrm{PbSe}$, and $\mathrm{PbS}$ films, respectively. This means the presence of compressive strain in all the investigated films. Since the film lattice parameters were derived from the THEED measurements, we assume that the compression occurs in the film plane. We may estimate the lattice mismatch, $\left(a_{\mathrm{film}}-a_{\mathrm{KCl}}\right) / a_{\mathrm{KCl}}$, where $a_{\mathrm{KCl}}=6.278 \AA$. The calculated lattice mismatch values are $+2.2 \%$ for $\mathrm{PbTe}$, $-2.6 \%$ for $\mathrm{PbSe}$, and $-6.0 \%$ for $\mathrm{PbS}$ films. This estimation shows that the observed mechanical compression is not caused by the lattice mismatch. The standard lattice parameters for $\mathrm{PbSe}$ and $\mathrm{PbS}$ relaxed crystals are lower than the $\mathrm{KCl}$ lattice constant. This means that due to the lattice mismatch one should observe a mechanical tension in these two layers, in the film planar direction. Instead, a mechanical compression is observed. This is a result of interactions between the atoms within the layer rather than between the layer atoms and the substrate atoms. To analyze this quantitatively, we determined mechanical parameters of the chalcogenide layers. The stress $\sigma$ was calculated using the following equation

$$
\sigma=\frac{E}{1-v} \times \frac{a-a_{\mathrm{st}}}{a_{\mathrm{st}}}
$$

where $E$ is the Young modulus and $v$ is the Poisson ratio. The values of $E$ and $v^{20}$ as well as the calculated values of $\sigma$ are gathered in Table II. The mean dislocation distance, $\langle L\rangle$, was calculated using the equation $\langle L\rangle=|\boldsymbol{b}| / \varepsilon$, where $|\boldsymbol{b}|=a / 2^{1 / 2}$ is the value of the Burgers vector and $\varepsilon=\Delta a / a_{\text {st. }}{ }^{21}$ The density of dislocations, $N$, that form at the growing layer/substrate interface is then equal to $(1 /\langle L\rangle)^{2}$. A degree of relaxation, $R=\left(a_{\mathrm{film}}-a_{\mathrm{KCl}}\right) /$ $\left(a_{\mathrm{st}}-a_{\mathrm{KCl}}\right)$, can be estimated for the deformation occurring in the film plane. The estimated values of $|\boldsymbol{b}|,\langle L\rangle, N$, and $R$ are shown in Table II. From the calculations, it follows that the most stress-sensitive layer is $\mathrm{PbS}$. This is not only related to the Young modulus but also to the dislocation density. The latter is associated with much higher strain values 
Table II. Mechanical parameters of the investigated films grown on $\mathrm{KCl}(001)$ substrates

\begin{tabular}{|c|c|c|c|c|c|c|c|c|c|}
\hline Layer & $E(\mathbf{G P a})$ & $v$ & $a(\AA)$ & $\Delta a / a_{\text {st }}(\%)$ & $\sigma(\mathbf{M P a})$ & $|b|(\AA)$ & $\langle L\rangle(\mathbf{n m})$ & $N\left(10^{6} / \mathrm{mm}^{2}\right)$ & $\boldsymbol{R}$ \\
\hline $\mathrm{PbTe}$ & 61.02 & 0.38 & 6.427 & -0.13 & -128 & 4.544 & 350 & 8.1 & \\
\hline $\mathrm{PbSe}$ & 66.33 & 0.33 & 6.117 & -0.11 & -109 & 4.326 & 393 & 6.5 & 0.99 \\
\hline $\mathrm{PbS}$ & 66.48 & 0.32 & 5.922 & -0.24 & -234 & 4.188 & 175 & 33.2 & 1.04 \\
\hline
\end{tabular}

The $E$ and $v$ values (for bulk crystals) are taken from Ref. 20.

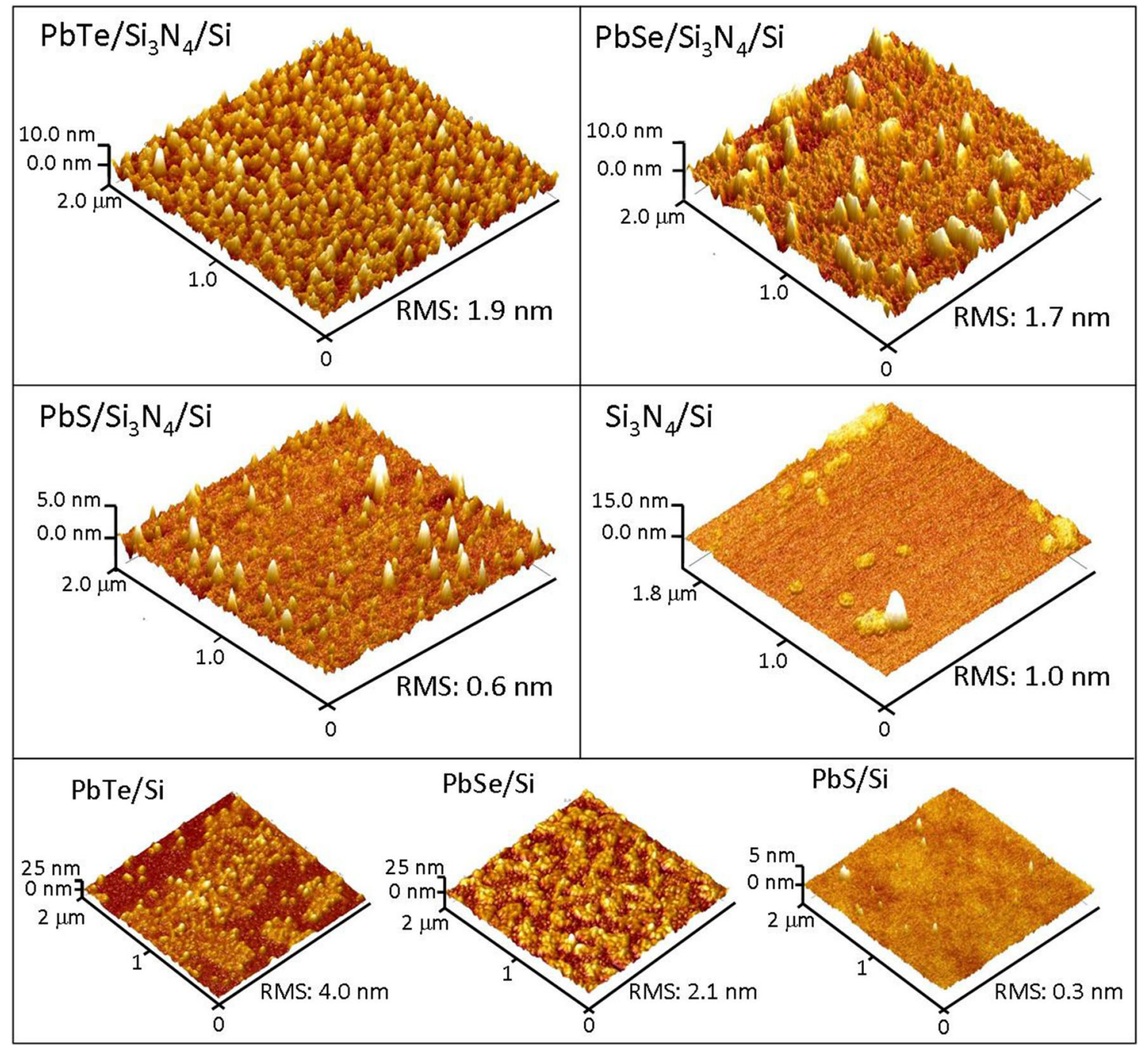

Fig. 3. (Top) AFM surface morphology of: $\mathrm{PbTe}, \mathrm{PbSe}$, and $\mathrm{PbS}$ films, grown on $\mathrm{Si}_{3} \mathrm{~N}_{4} / \mathrm{Si}(111)$ substrates, and the $\mathrm{Si} \mathrm{N}_{3} / \mathrm{Si}(111)$ substrate (Bottom) AFM images of $\mathrm{PbTe}$, PbSe, and $\mathrm{PbS}$ films grown on $\mathrm{Si}(111)$. RMS surface roughness values are indicated.

for the PbS film than in case of the other investigated chalcogenide layers. We also observe the following relations: the higher the degree of texture (crystallinity), the higher density of dislocations and the higher the strain. This indicates that in more polycrystalline films, the formation of grains and the presence of an atomic disorder at the grain boundaries constrain the dislocation formation at the first growth stages and reduce the strain during the prolonged layer growth. ${ }^{22}$

Figure 3 shows AFM images of $\mathrm{PbTe}, \mathrm{PbSe}$, and $\mathrm{PbS}$ film surfaces. The films were grown on Si(111) substrates and $\mathrm{Si}(111)$ covered with the 110-nmthick $\mathrm{Si}_{3} \mathrm{~N}_{4}$ buffer layer. The $\mathrm{Si}_{3} \mathrm{~N}_{4}$ layer has the root mean square (RMS) roughness $\approx 1 \mathrm{~nm}$. However, grains or islands with the lateral size 
(diameter) $\leq \approx 100 \mathrm{~nm}$ are infrequently observed. From comparing the grain structures of the layers grown on $\mathrm{Si}$ ans $\mathrm{Si}_{3} \mathrm{~N}_{4} / \mathrm{Si}$ substrates, we conclude that the $\mathrm{Si}_{3} \mathrm{~N}_{4}$ layer facilitated nucleation of lead chalcogenides at their first growth stages. The moderate roughness of $\mathrm{Si}_{3} \mathrm{~N}_{4}$, that is obviously higher than the atomically smooth $\mathrm{Si}$ surface, resulted in a creation of new crystallization centers, most probably at boundary regions between $\mathrm{Si}_{3} \mathrm{~N}_{4}$ grains. The resulting surface morphology of the films deposited on $\mathrm{Si}_{3} \mathrm{~N}_{4}$ is also more homogeneous and contains lower amounts of larger atom aggregates (clusters), compared to the respective layers grown on $\mathrm{Si}$. This is apparent in the case of the PbTe and $\mathrm{PbSe}$ films while the $\mathrm{PbS}$ is an exception. Additionally, the surface roughness of the films deposited on $\mathrm{Si}_{3} \mathrm{~N}_{4}$ decreased. The RMS roughnesses of $\mathrm{PbTe}, \mathrm{PbSe}$, and $\mathrm{PbS}$ films deposited on $\mathrm{Si}$ were $3.3 \mathrm{~nm}, 2.1 \mathrm{~nm}$, and $0.3 \mathrm{~nm}$, respectively. The films deposited on $\mathrm{Si}_{3} \mathrm{~N}_{4} / \mathrm{Si}$ under the same conditions showed the respective RMS values: $1.9 \mathrm{~nm}$, $1.7 \mathrm{~nm}$, and $0.6 \mathrm{~nm}$. The $\mathrm{PbS}$ layer deposited on $\mathrm{Si}$ already had very low surface roughness. Here, the RMS value did not decrease further and the $\mathrm{Si}_{3} \mathrm{~N}_{4}$ layer had no impact on the atom aggregates' formation.

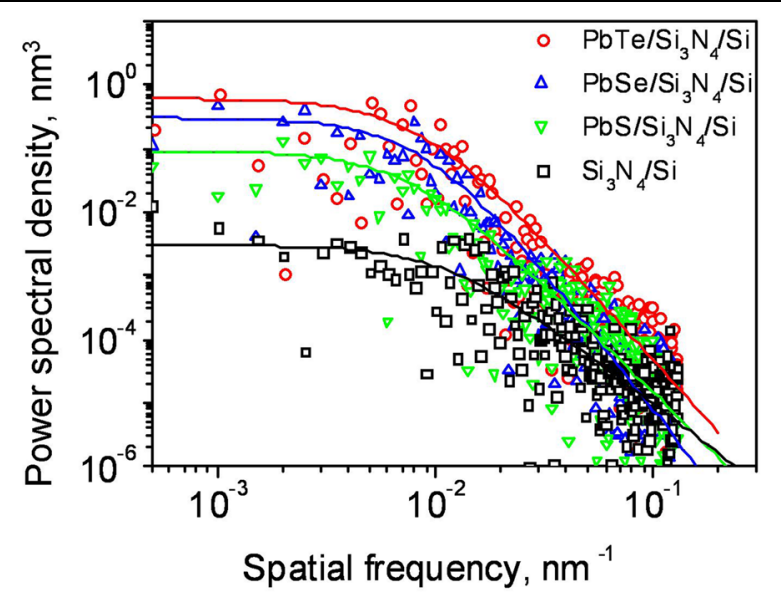

Fig. 4. Open symbols: power spectral density (PSD) of the PbTe, $\mathrm{PbSe}, \mathrm{PbS}$, and $\mathrm{Si}_{3} \mathrm{~N}_{4}$ surface profiles, determined from the AFM data. Lines: the results of fitting data (open symbols) by Eq. 1.
Surface morphologies of the investigated films were studied more in detail by the PSD analysis of their surface profiles. The calculated PSD function $\left(F_{\mathrm{PSD}}\right)$ values for the $\mathrm{PbTe}, \mathrm{PbSe}$, and $\mathrm{PbS}$ layers grown on $\mathrm{Si}_{3} \mathrm{~N}_{4} / \mathrm{Si}$ substrates, as well as the $F_{\mathrm{PSD}}$ of the $\mathrm{Si}_{3} \mathrm{~N}_{4}$ surface profile, are shown in Fig. 4 (open symbols). The $F_{\mathrm{PSD}}$ data were fitted by Eq. 1 . The fit results are shown in Fig. 4 (lines). The fit parameters $A, B$, and $C$ are gathered in Table III. The $A$ parameter, corresponding to the $F_{\mathrm{PSD}}$ values for lower spatial frequencies $f$ (i.e. the plateau regions for $f<\sim 10^{-2} \mathrm{~nm}^{-1}$ ), is the lowest for the $\mathrm{Si}_{3} \mathrm{~N}_{4}$ layer. It increases for the $\mathrm{PbS}, \mathrm{PbSe}$, and $\mathrm{PbTe}$ layers, respectively. These $f$ values correspond to average lateral distances of the order of $0.1 \mu \mathrm{m}$ and higher. They may be associated with regions having similar morphology and distinct from regions of the size $<\sim 0.1 \mu \mathrm{m}$ with different morphologies. The $B$ parameter, corresponding to the knee of the $F_{P S D}$ versus $f$ fit lines, is similar for $\mathrm{PbSe}, \mathrm{PbTe}$, and $\mathrm{PbS}$ layers (110-130 nm), and slightly lower $(90 \mathrm{~nm})$ for the $\mathrm{Si}_{3} \mathrm{~N}_{4}$ layer. For $f>\sim 10^{-2} \mathrm{~nm}^{-1}$, i.e. for lateral sizes lower than $100 \mathrm{~nm}$, the $F_{\mathrm{PSD}}$ function decreases. A measure of this decrease is the $C$ parameter. Its value is related to the inverse slope of the $F_{\mathrm{PSD}}$ function. According to Refs. 14, 23, and 24 , the $C=1$ indicates a growth mode associated with the viscous flow whereas $C=2, C=3$, and $C=4$ are related to condensation, bulk diffusion, and surface diffusion, respectively. For $\mathrm{PbS}$ and $\mathrm{PbTe}$ films, the growth mode is between condensation and bulk diffusion $(C=2.4$ and $C=2.8$, respectively). For $\mathrm{PbSe}, C=3.3$ relates to the growth mode between bulk and surface diffusion. At the PbSe surface, we observe single two-dimensional aggregates with the size of $\sim 200 \mathrm{~nm}$. According to the above analysis, formation of the aggregates was conditioned by the contribution of the species in the whole layer. A different situation occurs for the $\mathrm{PbS}$ film growth, where larger aggregate formation is associated mostly with condensation of the arriving plasma plume species at the $\mathrm{PbS}$ surface.

Finally, we complement our investigations by electrical characterization of the lead chalcogenide layers, grown on sapphire substrates. We carried out temperature-dependent conductivity measurements. The results are shown in Fig. 5 as the

Table III. Fit parameters $A, B$, and $C$ of the power spectral density Eq. 1

\begin{tabular}{lccc}
\hline Layer & $\boldsymbol{A}\left(\mathbf{n m}^{\mathbf{2}}\right)$ & $\boldsymbol{B}(\mathbf{n m})$ & $\frac{\boldsymbol{C}}{2.8}$ \\
\cline { 2 - 3 }$/ \mathrm{Si}_{3} \mathrm{~N}_{4} / \mathrm{Si}$ & 0.6 & 120 & 3.4 \\
$\mathrm{PbSe} / \mathrm{Si}_{3} \mathrm{~N}_{4} / \mathrm{Si}$ & 0.3 & 110 & 2.4 \\
$\mathrm{PbS} / \mathrm{Si}_{3} \mathrm{~N}_{4} / \mathrm{Si}$ & 0.09 & 130 & 1.6 \\
$\mathrm{Si}_{3} \mathrm{~N}_{4} / \mathrm{Si}$ & 0.003 & 90 & \\
\hline
\end{tabular}

The parameters were obtained by fitting Eq. 1 with the PSD of the surface morphologies of the investigated chalcogenide layers (see Fig. 4). 


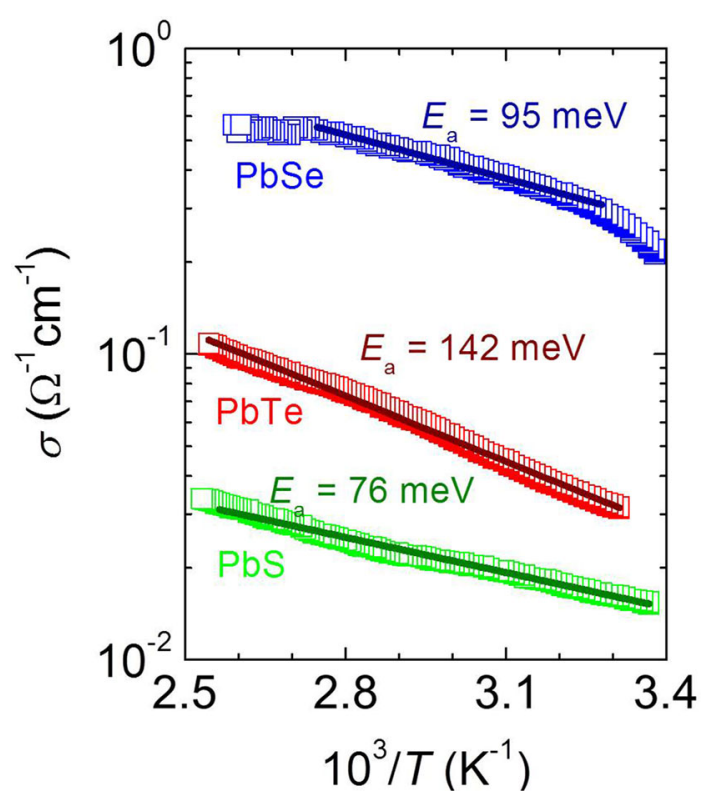

Fig. 5. Temperature dependence of the electrical conductivity of the $\mathrm{PbTe}, \mathrm{PbSe}$, and $\mathrm{PbS}$ films, measured in the $300-400 \mathrm{~K}$ range.

conductivity $\sigma$ versus inverse temperature $T^{-1}$ in a semi-log scale. The highest conductivity at room temperature (RT) was achieved by $\mathrm{PbSe}$, $\approx 0.2 \Omega^{-1} \mathrm{~cm}^{-1}$. PbTe and PbS layers have lower conductivities at RT, $\approx 0.03 \Omega^{-1} \mathrm{~cm}^{-1}$ and 0.015 $\Omega^{-1} \mathrm{~cm}^{-1}$, respectively. These conductivity values at $\mathrm{RT}$ are inversely related to the respective energy gaps of the investigated materials. Experimentally determined energy gaps for $\mathrm{PbSe}, \mathrm{PbTe}$, and $\mathrm{PbS}$ are $0.26-0.29,0.29-0.32$, and $0.37-0.40 \mathrm{eV}$, respectively. ${ }^{25,26}$ This indicates that at temperatures close to RT, the intrinsic conduction dominates. The observed activation-type $\sigma(T)$ behavior, with determined activation energies of 76-142 meV, is associated with the presence of deep donor states. Most probably, these states are generated by Se, Te, or S vacancies in the respective films. ${ }^{25}$ Such vacancies can form during the PLD growth due to different sticking coefficients of chalcogen and lead adatoms.

\section{CONCLUSIONS}

We obtained lead chalcogenide films, $\mathrm{PbTe}, \mathrm{PbSe}$ and $\mathrm{PbS}$, by the PLD method. The layers show good structural quality. The degree of texture slightly varied among the three chalcogenides and was the highest for the $\mathrm{PbS}$ layer. The highest structural order of $\mathrm{PbS}$ was associated with the smoothest surface morphology, the highest density of dislocations that formed at the film/substrate interface, and the highest compressive strain in the film plane direction. The latter two phenomena were attributed to the relatively low density of grain boundaries that could constrain the dislocation formation and reduce the strain. At the surface of the lead chalcogenide films, atoms form aggregates (clusters). In case of the PbSe and PbS films, the density of these aggregates decreased when an additional layer of $\mathrm{Si}_{3} \mathrm{~N}_{4}$ was deposited on $\mathrm{Si}$ before lead chalcogenide film deposition. The PSD analysis of the film surface profiles indicated different mechanisms of larger aggregate formation during the $\mathrm{PLD}$ growth. In PbS and PbTe films, larger aggregates formed predominantly by the condensation of an arriving plasma plume species at the film surface. For PbSe, additional bulk diffusion processes within the layers contributed to the resulting surface geometry. The investigations were complemented by electrical measurements of the deposited films. At room temperature, the electrical conductivity is associated mostly with the intrinsic conduction which is related to different energy gaps of these materials. In addition, activation behavior of the $\sigma(T)$ dependencies indicated a contribution of deep energy states (donors) generated by chalcogenide atom vacancies.

\section{OPEN ACCESS}

This article is distributed under the terms of the Creative Commons Attribution 4.0 International License (http://creativecommons.org/licenses/by/4.0/), which permits unrestricted use, distribution, and reproduction in any medium, provided you give appropriate credit to the original author(s) and the source, provide a link to the Creative Commons license, and indicate if changes were made.

\section{REFERENCES}

1. B. Weng, J. Qiu, L. Zhao, Z. Yuan, C. Chang, and Z. Shi, Proc. SPIE 8993, 899311 (2013).

2. J. Wang, T. Zens, J. Hu, P. Becla, A.M. Agarwal, and L.C. Kimerling, Proc. SPIE 8034, 80340K (2011).

3. V. Kasiyan, Z. Dashevsky, C.M. Schwarz, M. Shatkhin, E. Flitsiyan, L. Chernyak, and D. Khokhlov, J. Appl. Phys. 112,086101 (2012).

4. C. Sierra, M.C. Torquemada, G. Vergara, M.T. Rodrigo, C. Gutiérrez, G. Pérez, I. Génova, I. Catalán, L.J. Gómez, V. Villamayor, M. Álvarez, D. Fernández, M.T. Magaz, and R.M. Almazán, Sens. Actuators B 190, 464 (2014).

5. M.C. Torquemada, V. Villamayor, L.J. Gómez, G. Vergara, M.T. Rodrigo, G. Pérez, I. Génova, I. Catalán, D. Fernández, R.M. Almazán, M. Álvarez, C. Sierra, C.M. Gutiérrez, M.T. Magaz, and J. Plaza, Sens. Actuators A 199, 297 (2013).

6. B. Weng, J. Qiu, L. Zhao, C. Chang, and Z. Shi, Appl. Phys. Lett. 104, 121111 (2014).

7. J. Wang, J. Hu, P. Becla, A.M. Agarwal, and L.C. Kimerling, J. Appl. Phys. 110, 083719 (2011).

8. S. Kouissa, A. Djemel, M.S. Aida, and M.A. Djouadi, Sens. Transducers 193, 106 (2015).

9. YuI Ravich, B.A. Efimova, and I.A. Smirnov, Semiconducting Lead Chalcogenides (New York: Plenum Press, 1970).

10. I.O. Rudyi, I.V. Kurilo, M.S. Frugynskyj, M. Kuzma, J. Zawislak, and I.S. Virt, Appl. Surf. Sci. 154-155, 206 (2000).

11. I.S. Virt, T.P. Shkumbatyuk, I.V. Kurilo, I.O. Rudyi, T. Ye, Lopatynskyi, L.F. Linnik, V.V. Tetyorkin, and A.G. Phedorov, Semiconductors 44, 544 (2010).

12. I.S. Virt, I.O. Rudyj, I.V. Kurilo, I.Y. Lopatynskyi, L.F. Linnik, V.V. Tetyorkin, P. Potera, and G. Luka, Semiconductors 47, 997 (2013).

13. S. Singh and S. Basu, Surf. Coat. Technol. 201, 952 (2006). 
14. T. Itoh and N. Yamauchi, Appl. Surf. Sci. 253, 6196 (2007).

15. I.S. Virt, Y. Tur, I.O. Rudyi, I.Y. Lopatynskyi, M.S. Frugynskyi, I.V. Kurilo, E. Lusakowska, B.S. Witkowski, and G. Luka, J. Cryst. Growth 432, 19 (2015).

16. X. Sun, K. Gao, X. Pang, H. Yang, and A.A. Volinsky, Appl. Surf. Sci. 356, 978 (2015).

17. S. Prabahar, N. Suryanarayanan, K. Rajasekar, and S. Srikanth, Chalcogenide Lett. 6, 203 (2009).

18. J. Qiu, B. Weng, Z. Yuan, and Z. Shi, J. Appl. Phys. 113, 103102 (2013)

19. H.C. Casey Jr. and M.B. Panish, Heterostructure Lasers. Part B: Materials and Operating Characteristics (Academic Press, New York, 1978).

20. A. Bali, R. Chetty, R.C. Mallik, and A.I.P. Conf, Proc. 1591, 1118 (2014).
21. E. Wintersberger, N. Hrauda, D. Kriegner, M. Keplinger, G. Springholz, J. Stangl, G. Bauer, J. Oswald, T. Belytschko, C. Deiter, F. Bertram, and O.H. Seeck, Appl. Phys. Lett. 96, 131905 (2010).

22. W.D. Callister and D.G. Rethwisch, Materials Science and Engineering: An Introduction, 9th ed. (Hoboken: Wiley, 2014).

23. D.G. Stearns, P.B. Mirkarimi, and E. Spiller, Thin Solid Films 446, 37 (2004).

24. W.M. Tong and R.S. Williams, Annu. Rev. Phys. Chem. 45, 401 (1994).

25. W.-F. Li, Ch-M Fang, M. Dijkstra, and M.A. van Huis, J. Phys.: Condens. Matter 27, 355801 (2015).

26. W.H. Strehlow and E.L. Cook, J. Phys. Chem. Ref. Data 2, 163 (1973). 